\title{
Industry 4.0 and the Effects of Improving Humanless Technology on Business Management
}

\author{
İpek Cansev Tavukçuoğlu, Metehan Tolon
}

\begin{abstract}
Every age has its own specific conditions and requirements. The secrets of being permanent, sustainable and competitive in today's business world are hidden adapt to the trends of the times. This age is called information age, global age or communication age. On the agenda of the multinational corporations forming the rings of the international value chain, the concept of Industry 4.0 and the possible reflection of this concept in manufacturing and service fields play an important role. This new process, also called the new (4th) Industrial Revolution, points to a higher level of automation. It is foreseen that this new form of artificial intelligence, internet of objects, vehicles without drivers, 3d printer, nanotechnology, all vehicles and machines involved in production processes will be stored in the cloud system for production using sensors. This study discusses the basic features of Industry 4.0 conceptualizing from the year 2011 on the world and possible reflections on business management.
\end{abstract}

Keywords - industry 4.0, marketing, business management, Internet of things

\section{Introduction}

For the manufacturing sector, which was based on machinery and animal husbandry before the industrial revolution took place, nothing was the same after the invention of steam engine machine.

\section{İpek Cansev TAVUKCUOGLU}

Gazi University / Institute of Social Sciences

Ankara, Turkey

Metehan TOLON

Associate Professor

Gazi University /School of Economics and Administrative Sciences, Department of Business Administration

Ankara, Turkey
Production patterns and capacities increased and lifestyles changed. The Industrial Revolution, which led to socioeconomic and cultural changes in the world, took place over a long period of time. From this perspective it is possible to talk about 3 different Industrial revolutions which have extremely different structures and effects from each other till now. Introduce with the invention of the steam engine at the end of the 18th century in UK the concept of industry 1.0 was improved with the concept of industry 2.0 when Henry Ford invented mass production, and it kept being developed as industry 3.0 thanks to the development of the first programmable logic controllers (PLCs) and increasingly powerful computer systems which leads the way to digitalization. [1]. Today in accordance with the expections and needs, communication between all the departmants which are releated with the industrial production, which is called Internet of the things and real time access for all data is the concept of Industry 4.0. The term Industry 4.0 has been used in Germany for the first time in 2011 at Hannover Industrial Fair. [2]

\section{Definition Of Industry 4.0}

A new industrial revolution means the development of existing methods. The distinguishing feature of Industry 4.0 is the simultaneous production of all vehicles and machines involved in the production process through the interaction of sensors and internet. It is foreseen that this new form of the industry, which will be stored in the cloud system, will overcome the rigors of space and time. Industry 4.0, which includes advanced engineering and full integration between systems, is expected to pass high valueadded production-based competition rather than 
competition based on cheap labor in the international arena. [3]. The technology that triggers digital conversion in Industry 4.0 is shortly called CAMPS. C (Cloud) cloud computing, A (Analytics) big data analysis, M (Mobility) mobile world, $\mathrm{P}$ (Productivity) productivity and S (security) cyber security. In other words, an institution that wants to perform digital transformation should start with cloud computing and end security and transformation.[4] This will not only be the digital transformation of that company, but it will also ensure compliance with industry 4.0. In addition, it stands out as another technology that has augmented reality, additive manufacturing, 3-D printing, intelligent robots, simulation, horizontal / vertical software-system integration, internet of the things. [5]

In particular for developing countries, industry 4.0 will be understood and integration into national industries will determine the new roles these countries will assume in the international division of labor. Apart from the nice aspects that Industry 4.0 has, there are also some negative aspects that will make our life difficult. The final words of the writer and president of the World Economic Forum, Klaus Schwab, before Davos in Foreign Affairs before 2016: "Finally, everything is connected to people and their values. We should shape a future that takes people's foreground and strengthens them. It is also true that the 4th Industrial Revolution, in its most pessimistic and humane manner, carries the danger of depriving the heart and the spirit by 'robotizing' the human. But humanity can also raise awareness of a new collective and collectively owned values. It is our responsibility to make it happen. In addition, the difficulties encountered in adapting and programming all of the machines to be used in the production processes to the standards of Industry 4.0 are the other negatives that can be expected to be costly. This study discusses the basic features of Industry 4.0 conceptualizing from the year 2011 on the world and possible reflections on business management.

In the final report of Acatech's Industry 4.0 forum (Acatech, 2013), the following are the distinguishing innovations that this new era is bringing about:

- Global interaction of storage systems and resources with machines,
- The development of unique intelligent products with location knowledge,

- The history of smart factories adapting to product specifications, providing resource optimization, the realization of new business models (such as new services resulting from the use of Big Data)

- New social infrastructure in the workplace for the employees, business structure sensitive to individual differences,

- Better work / life balance,

- Responding to individual consumer requests,

- Intelligent software developed for immediate engineering and instantaneous response to problems. [6]

\section{Components of Industry 4.0}

\section{A. Cyber-Physical Systems}

Many companies still use unmanaged management and production systems. However, with increased connectivity, secure communication based on the identification of machines and the management of access to machines will gain importance in order to protect critical industrial systems and production lines against cyber security threats. The Cyber-Physical Systems, which create a vast network of communications with the Internet of objects, and thus move to lifting the boundaries between real and virtual worlds, are among the forces behind Industry 4.0.

\section{B. Horizontal and Vertical Integration}

Horizontal Integration means that each step in the production and planning process is seamless to itself, as well as a seamless flow of steps between production and planning processes of different businesses. Vertical Integration means to provide seamless communication and flow between technological infrastructure used in all processes, not between processes. Vertical and horizontal integration enables Industry 4.0 to respond quickly to changes and problems in production processes, to facilitate customer specific and personalized 
production, to increase resource efficiency, and to optimize the global supply chain.

\section{Internet of Things (IoT)}

This system, which we can summarize as "things, physically connecting the devices to each other and functioning internally" is of great importance in terms of facilitating our daily life. The data generated by the interaction between things makes it possible to carry out the industrial processes in a much more controlled manner, make more detailed analyzes, We can make decisions. This structure, also called "Internet of Industrial things", makes smart factories even smarter. Thus, many different and complex products can be produced in shorter time and at optimum quality.

\section{Smart Robots}

Manufacturers in various sectors are benefiting from robots for a long time in their operations. In the world, robot technology is now becoming more autonomous, flexible and collaborative by improving its competencies and reducing the cost of ownership. In the following period, robots will interact with each other, work side by side with people more securely, and improve their learning abilities. With industry 4.0, robots will be able to communicate with each other to get a complete robotic approach. For example, the robot responsible for painting would be able to serve another point by updating its software if another area is needed. Moreover, without any human-induced command, it will be based purely on its own observation, analysis and foresight.

\section{E. Big Data}

According to Cisco's 2013 "The Internet of Everything" study, by 2016, the number of electronic devices connected to the system will exceed 20 billion, and the data size collected from these devices will reach one zeta byte ( 1 zeta byte $=$ 1 billion terabytes). With such a large amount of data being held on secure systems and being analyzed and transformed into meaningful information, businesses in particular are starting to gain valuable information. If possible faults can be anticipated and precautions can be taken, the opportunities can be noticed beforehand and can be acted quickly. Costs of production can be reduced while service-maintenance processes are facilitated.
In short, analysis and forecasting are facilitated in every aspect from customer expectancies to market movements, and decision-making processes and value chains are improved.

\section{F. Cloud Computing}

With Cloud Computing, users can use applications on the internet via the computers of the service provider instead of keeping the applications necessary for the business in the on-site computers or data centers. Thus, more economical, flexible and agile data management is achieved. Cloud Computing encompasses three models: IaaS (Infrastructure as a Service), which is focused on hardware and IT infrastructure management, Platform as a Service (PaaS), which provides tools for development, and SaaS (Software as a Service), which enables the use of software on servers. Industry 4.0 also benefits from Cloud Computing. The inherent abundance of storage space, advanced computing power, etc., provide a great opportunity to collect, analyze and store data, which is a very important asset in industrial production. By engaging in communication between intelligent devices, Big Data, Internet of Things and Cloud Computing work together to open a new era in the industry.

\section{G. Virtual Reality}

It is not right to reconcile the concept of Virtual Reality with video games and entertainment. This concept applies to the health sector from military applications; Education, tourism, architecture or sales-marketing can be applied in many different areas. Of course, the industry is also one of these areas. Industrial production planning, design, production, service, maintenance, testing and quality control can be utilized at any point in the virtual environment. Therefore, Virtual Reality emerges as one of the key features of Industry 4.0. For example, it does not have to wait for the fab to be physically installed to see how efficiently a fabrication works. In the industry 4.0 framework, the factory is installed, operated and analyzed in a virtual environment. Not only is the factory generic, but all the individual production processes or machines can be examined and elaborated. For example, the staff responsible for the servicing and maintenance of machines can receive hands-on training in the virtual environment, even the unreachable parts of 
the machine can be observed and error probabilities can be predicted. One of the sectors that benefits the most from Virtual Reality within the scope of Industry 4.0 is automotive. Virtual reality is used not only in this sector but also in the sales phase, and potential customers can experience driving experience through simulations before buying a car. Options such as optional applications, color or accessory changes are also available in the Virtual Reality environment.

\section{H. Cyber Security}

Virtual environments, remote access possibilities, data stored in the cloud ... In order to take full advantage of the advantages of these and similar possibilities, the security must also be maximized in such environments. Because the information, especially the business data, is very valuable. In the industry 4.0 environment, it is important that data is only available to authorized personnel, and that data sources and integrity can be verified. For example, in a production facility, critical data need to be accessible only to authorized personnel. It is imperative that all the information entered in the devices be taken from reliable sources and that any precautions should be taken so that the correctness is not at risk. Thus, businesses can safeguard their knowledge and data. In this context, Industry 4.0 continues to evolve, both in terms of security and power.

\section{Lights-out Manufacturing}

Robotics and advanced automation systems that have evolved since the Third Industrial Revolution have enabled the establishment of $7 / 24$ production facilities with minimal need for human intervention. In these environments, which do not require the human factor to be in operation at all times, it has come to be thought that low-level illumination or production can be carried out in total darkness, so that the idea of an unmanned factory has been put forward. This production methodology, called lights-out manufacturing, is considered synonymous with full automation. The integrated and uninterrupted development and production processes adopted by Industry 4.0 are moving towards this ultimate goal. With advanced automation and digitalization, the human-focused workforce will focus on far more diverse areas and many factories and production facilities will start to produce in the dark with Industry 4.0. [7] [8]

\section{J. Augmented Reality}

Augmented reality is a live direct or indirect view of a new perception environment created by combining computer generated and sensory input, such as audio, video, graphics, or GPS data, with the physical, real world environment of the animated elements. Inputs that appeal to the human senses with increased reality and move their feelings are modified and enriched by the computer and presented to the perception of the emerging new reality. Enrichment takes place in real time and interacts with the surrounding objects. Augmented Reality can interact with information that creates the user's reality environment and other issues. Artificial information and articles about the surrounding environment are compatible with the real world. These systems are now in their own crawl phase, but in the future companies will use the increased reality more intensely to improve decision making and business procedures. In the virtual world, operators can click on a button to change their parameters to interact with their machine and to receive operational data and maintenance instructions. [9]

\section{Benefits Of Industry 4.0}

\section{A. Productivity}

Over the next 5-10 years, many companies will be able to adapt to Industry 4.0 and production costs will be improved by $15-25 \%$ excluding raw materials. It is foreseen that this improvement will only have an impact of 90-150 billion Euros on the manufacturing sector in Germany. When raw material costs are included, total productivity gains will range from 5 to 8 percent.

\section{B. Revenue Increase}

Thanks to Industry 4.0, manufacturers' demand for advanced equipment and new data will increase in parallel with the increasing demand for customer personalized products. In the case of Germany, this development is expected to increase GDP (gross domestic product) by $1 \%$, bringing annual growth of around $\$ 30$ billion.

\section{Employment}

Despite many opposing views on employment, Industry 4.0 is expected to increase 
employment by $6-10 \%$ in the manufacturing sector. Demand for the new workforce will be felt most in the mechanical-engineering sector. On the other hand, while the employment opportunities for lowskilled workforce are declining, the demand for staff with different competencies will increase.

\section{Investment}

In order to be able to adapt the production processes to 'Industry 4.0', it is envisaged to allocate 1 to 1.5 percent of the producers' production. This figure is expected to be 250 billion euros for the next 10 years in Germany. [10]

\section{Conclusion}

The biggest innovation in Industry 4.0 is robots that work with all these systems. Humanity must inevitably become accustomed to the existence of robots as all other living beings. Because robots and machines are becoming more and more self-managing beings rather than vehicles. Although automation will increase day by day, human needs will always be there. From the programming of the robot to its maintenance, the human being is again the leading figure. Because, even in a robot-indexed system, the leader must be creative people. Especially in the future world; Creator and leadership feature will be one step ahead of the developed white-collar. Fabrics, which are the most widespread use of robots, should make this change much more efficiently. Because, as a requirement of Industry 4.0, robots in factories are becoming more and more active members of working and working teams, rather than being the only tool to help people. For this reason, it is of utmost importance that people and robots work in the most proactively harmonious manner.

In the future, with the development of more active mixed groups, people and robots will receive mutual support from each other. Robots will shorten people's compulsory working hours so that they can improve their personal and professional development. They will also spare a lot of time.

As a result; In an environment where robots and human interaction are so intense, the ability to manage the communication between humans and robots in a healthy way depends on an effective management strategy. [11]

\section{References}

[1]. Bosch, R. Product Catalog "Industry 4.0 at Bosch" https://www.bosch-

si.com/media/en/bosch_si/manufacturing/icons_1/ma/rober t_bosch_produktkatalog.pdf

[2]. Alcin, S. "A New Theme For Production : Industry 4.0" vol: 8 Journal Of Life Economics, 2016.

[3]. Schwab, K. “The Fourth Industrial Revolution”, 2016

[4]. Tavukcuoglu, C. "The effect of industry 4.0 on logistics in 10 questions ", 2017 http://www.lojistikhatti.com/haber/2017/01/sanayi-4-Oinlojistige-etkileri

[5].Banger G. "Industry 4.0 and Smart Business", 2016

[6]. Acatech, National Academy of Science and Engineering, "Recommendations for implementing the strategic initiative INDUSTRIE 4.0” 2013 http://www.acatech.de/fileadmin/user_upload/Baumstruktu r_nach_Website/Acatech/root/de/Material_fuer_Sonderseit en/Industrie_4.0/Final_report_Industrie_4.0_accessible.p $d f$

[7]. Siemens, Catalog "On the way to industry 4.0" siemens.com.tr/dijitalfabrikalar

[8] Tusiad, BCG Catalog "Industry 4.0 as a requirement for Turkey's global competitiveness" 2016 www. tusiad.org

[9] http://www.endustri40.com/artirilmis-gerceklik-augmentedreality

[10]https://www.bcgperspectives.com/content/articles/engineere d_products_project_business_industry_40_future_producti vity_growth_manufacturing_industries/?chapter=3\#chapte $r 3$

[11] Aegean Region Chamber of Industry Catalog, "Industry 4.0” 2015 http://www.inovasyon.org/pdf/EBSO.Sanayi4.0_Raporu.Ekim.2015.pdf

About Author (s): İpek Cansev TAVUKCUOGLU

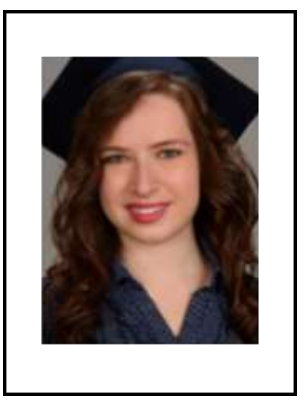

Gazi University / Institute of Social

Sciences / Master Student

Research Interests: Consumer

behaviors, Marketing, Production

Systems, Industry 4.0

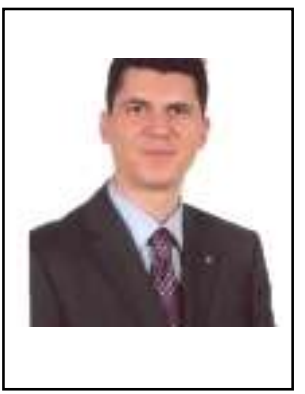

Gazi University/ School of Economics and Administrative Sciences, Department of Business Administration / Associate Professor

Research Interests: Consumer behaviors, Customer relations management, Direct Marketing, 